\title{
ANTE LA CRISIS MÁS CAPITALISMO
}

\section{JUAN ANTONIO MORENO URBANEJA*, Gerente de Adivin}

Resumen: el único efecto positivo de esta dramática crisis será darnos cuenta de que el socialismo fagocitario del dinero ajeno nos ha dejado sin recursos para reaccionar, y eso daña sobre todo a los más pobres. Ahora es un buen momento para optar de una vez por el capitalismo que nos hace más ricos y más libres.

capitalismo, liberalismo, socialismo, pobreza, crisis económica

Sumary: the only positive effect of this dramatic crisis will be to realize that the phagocitary socialism of foreign money has left us without resources to react, and that damages affects specially the poorest. Now is a good time to decide once and for all in favor of capitalism which will make us richer and more free.

capitalism, liberalism, socialism, poverty, economic crisis

Hace unos años, aprovechando el cambio de milenio, la organización The Latino Coalition quiso dar su célebre premio a la persona o institución del mundo que más hubiera ayudado en el siglo XX a la integración y promoción de los hispanos y de otras minorías en América ${ }^{1}$.

Cualquier socialista pensaría que se lo dieron a una de las instituciones públicas redistribuidoras de riquezas: UNICEF, ONU, Banco Mundial, Fondo Monetario Internacional, o a una de las instituciones de caridad de la Iglesia Católica o de las Iglesias evangélicas, o a políticos redistribudores como Hugo Chávez o Fidel Castro. ¿Quién piensan estos hispanos que han hecho más por su promoción personal? Evidentemente ninguna de las opciones anteriores porque las ayudas redistributivas nunca han ayudado a salir de la pobreza a medio y largo plazo. El premio se lo dieron a McDonald's.

McDonald's dio desde sus inicios muchas oportunidades de empleo a las minorías. Numerosos hispanos tuvieron la confianza de McDonald's para montar su propio restaurante mediante créditos bancarios avalados por el prestigio de la Multinacional. Todos estos hispanos que en los años 60 salieron de la pobreza montando su propio negocio, ahora son dueños de numerosas franquicias y viven

\footnotetext{
*jam@adivin.com

${ }^{1}$ El premio se llama Arches to Ownership.
} 
lujosamente. Además millares de hispanos inmigrantes recién llegados obtuvieron y obtienen su primer empleo en McDonald's ${ }^{2}$.

Y como dice su presidente en EEUU, el también hispano Ralph Álvarez, todo este beneficio a la comunidad hispana se ha realizado siempre sin ningún tipo de discriminación positiva, sin ninguna finalidad que no sea la de propio beneficio de la empresa. Los directivos de McDonald's descubrieron que el perfil hispano, trabajador, leal, con pocos recursos y dispuesto a empezar cobrando poco, era muy adecuado para su expansión mediante franquicias. La Multinacional se enriqueció del único modo que se puede enriquecer en el capitalismo: enriqueciendo a los demás: a sus socios, a sus trabajadores, a sus proveedores y además dando unas hamburguesas riquísimas a los consumidores que han respondido visitando masivamente sus limpios restaurantes. McDonald's da oportunidades para trabajar y promocionarse. Eso es lo quieren los pobres: no quieren la humillante limosna institucional que hoy les cae de arriba y no saben si mañana también. Quieren una oportunidad para generar riquezas por sí solos, y eso sólo lo puede hacer la empresa privada.

Existen dos modelos muy distintos de ayuda a los pobres: la dádiva redistributiva que quita a los ricos para darlo a los pobres, o las oportunidades de trabajo que ofrecen las empresas buscando su propio lucro. La primera se ha demostrado machaconamente ineficaz desde mediado de siglo XX, pese a lo cual sigue siendo el modelo favorito de la izquierda, de la derecha tradicional y de los católicos con nula cultura económica ${ }^{3}$. La segunda, como en el ejemplo que hemos visto, ha permitido que los pobres se enriquezcan a medio y largo plazo, dejando de ser pobres.

${ }^{2}$ Datos:

- Más de un tercio de los propietarios de franquicias de McDonald's en los Estados Unidos son miembros de minorías y mujeres (Revista Hispanic Business)

- McDonald's es la primera entre las 40 compañías más importantes para los hispanos (Revista Hispanic Business)

- McDonald's está en el puesto 13 entre las 50 mejores compañías para las empresarias latinas del 2003 al 2004 (Latina Style)

- McDonald's es la mejor compañía para las minorías (Fortune)

- Dos tercios de los puestos gerenciales intermedios y superiores de McDonald's están ocupados por personas que comenzaron su carrera en la compañía como empleados de un restaurante (Latina Style)

- Los programas de entrenamiento completo como los de McDonald's le dan a las personas de origen hispano las herramientas que necesitan para tener éxito en una compañía estadounidense. Muchos también aprendieron inglés como segundo idioma a través de estos trabajos (Encuesta realizada por DePosada para la revista Hispanic Business)

3 Así nos lo ha recordado el Papa Benedicto XVI: “es innegable que las políticas marcadamente asistencialistas están en el origen de muchos fracasos en la ayuda a los países pobres. Parece que, actualmente, el verdadero proyecto a medio y largo plazo sea el invertir en la formación de las personas y en desarrollar de manera integrada una cultura de la iniciativa. Si bien las actividades económicas necesitan un contexto favorable para su desarrollo, esto no significa que se deba distraer la atención de los problemas del beneficio. Aunque se haya subrayado oportunamente que el aumento de la renta per capita no puede ser el fin absoluto de la acción político-económica, no se ha de olvidar, sin embargo, que ésta representa un instrumento importante para alcanzar el objetivo de la lucha contra el hambre y la pobreza absoluta. Desde este punto de vista, no hay que hacerse ilusiones pensando que una política de pura redistribución de la riqueza existente resuelva el problema de manera definitiva. En efecto, el 
El socialismo afirma erróneamente que "la riqueza está injustamente distribuida". Pero no puede estar ni bien ni mal distribuida porque la riqueza nunca se origina tras una distribución ni divina ni supraestatal. La riqueza se genera desde abajo hacia arriba. La crea el trabajo de cada persona y de cada empresa. Se genera, no se distribuye. Y cuando la intentamos distribuir la dilapidamos.

El informe Gwartney ${ }^{4}$ nos dice que en la última década el PIB per cápita mundial creció un 2,2\%, prácticamente el doble del crecimiento experimentado en las décadas pasadas. La pobreza absoluta (no la relativa, siempre somos más pobres que "alguien") se redujo del $40 \%$ al 21\% desde 1981 a nivel mundial hasta la fecha. Es tal vez uno de los fenómenos humanos más masivos e importantes de la historia. Desde el año 2000, la tasa de crecimiento se ha acelerado al 3,2\%. Esas tasas de crecimiento son mucho más altas en los países con economías más capitalistas, con más libertad económica.

El informe Gwartney entiende por "libertad económica" la mayor capacidad de los ciudadanos para hacer lo que estimen oportuno con sus propiedades (usarlas, intercambiarlas, cederlas), "siempre y cuando sus acciones no violenten los derechos -idénticos- de los demás". Pues bien, sus datos relacionan matemáticamente la libertad económica (capitalismo) con el nivel de ingresos. Mientras más liberalizan su actividad económica los países, más aumenta su PIB ${ }^{5}$. Esto no debería sorprendernos, pero -por desgracia- los prejuicios contra el afán de lucro y el derecho de propiedad todavía llevan a muchos a pensar que la coacción estatal es la mejor ayuda a los pobres.

A la hora de puntuar a los países sometidos a estudio, Gwartney y compañía tienen en cuenta cinco factores:

- El tamaño del Estado

- La seguridad de la propiedad

- La estabilidad monetaria

- La libertad para comerciar con el exterior

valor de la riqueza en una economía moderna depende de manera determinante de la capacidad de crear rédito presente y futuro. Por eso, la creación de valor resulta un vínculo ineludible, que se debe tener en cuenta si se quiere luchar de modo eficaz y duradero contra la pobreza material" (Mensaje del 1 De Enero de 2009 para la Celebración de la Jornada Mundial de la Paz). Las letras negritas mías.

${ }^{4}$ Este informe o índice lo elabora el Stavros Center for the Advancement of Free Enterprise and Economic Education de la Universidad de la Florida, junto a Robert Lawson de la Capital University. Los datos que uso corresponden al índice del 2005 que recoge datos de más de 70 instituciones de todo el mundo en 99 países.

${ }^{5}$ Datos:

- Las economías menos libres tienen un PIB per cápita de unos 3.300\$.

- Las que están inmediatamente por encima de ellas en el ranking se mueven en torno a los 6.100\$.

- Las del siguiente tramo ya alcanzan los $10.773 \$$

- Las más libres los $26.000 \$$. 
- Los bajos niveles de regulación.

Respecto a la libertad de comercio:

\begin{tabular}{|l|l|}
\hline Los países con más libertad son & Los países con menos libertad \\
\hline 1. Hong Kong & 218. República del Congo \\
2. Singapur & 219. Angola \\
2. Nueva Zelanda & 221. Birmania \\
4. Suiza & 222. Zimbabwe \\
5. Estados Unidos & \\
6. Reino Unido & \\
7. Canadá & \\
8. Estonia & \\
9. Irlanda & \\
10.Australia. &
\end{tabular}

La vida es mucho más agradable en los países más libres. Allí donde hay poca o ninguna libertad económica, la vida es un infierno para todo el mundo, menos para quienes están en el poder; y a veces ni siquiera éstos se libran... Del referido informe se desprende también que es mejor ser pobre en un país libre que en uno que no lo es. En los países más libres, el 10\% más pobre de la población gana más de 7.300\$ de media al año, frente a los $905 \$$ de sus homólogos en los países más pobres. Y en las sociedades libres los más pobres consiguen dejar de serlo en esa o en la generación siguiente.

En el capitalismo ¿quién es el rico? ¿quién es el que se enriquece? No el que tiene riqueza sino el que la genera, el que se enriquece. Quizás en el pasado y ahora en ciertas sociedades no capitalistas exista la figura del rico heredero que, haga lo que haga, siempre tendrá riqueza. Tiene riqueza aunque no la genere. Pero eso no tiene nada que ver con la realidad diaria de nuestra sociedad abierta. Una de las notas del capitalismo es que uno sólo se puede enriquecer interactuando y enriqueciendo a los demás: empleados, proveedores y clientes. Se enriquece el que tiene voluntad y capacidad de generar un beneficio a los demás en condiciones tales de ser recompensado. 
No existe en la realidad ningún país del mundo con un capitalismo puro. Si existiera, ese sería el lugar más solidario y rico del planeta: porque el enriquecimiento de unos sólo sería posible a través de la generación de beneficios de otros. En los países con más libertad económica existen tal cantidad de empresas, de intercambio de ideas, de recursos, que es más fácil que una persona o equipo de personas pueda generar beneficio a los demás en condiciones tales de ser recompensados. En las zonas con bajo grado de capitalismo, libertad y democracia -como Zimbabwe- podemos encontrar personas trabajadoras e inteligentes con iniciativas empresariales, pero allí el tejido empresarial es tan pobre que tienen pocas oportunidades de dar beneficio y menos de ser recompensado económicamente. Por eso Bill Gates, Steve job, Walt Disney y Rockefeller nacieron en EEUU, no en Zimbabwe. Las numerosas oportunidades que ofrece EEUU le convierte en la nación donde se generan de la nada más multimillonarios, donde se acoge e integran más inmigrantes desde hace siglos y donde más rápidamente las familias pobres dejan de ser pobres ${ }^{6}$.

Los ricos, los que crean riquezas, son los que tienen las ideas y asumen riesgos con sus capitales. El resto de nosotros colaboramos, no porque no nos quede más remedio, sino porque la división del trabajo es mucho más productiva que procurarnos nuestra propia comida, vestidos y medicinas. El capitalismo no está basado en la explotación y "alienación" de los trabajadores en su trabajo sino en la inevitable creación de mejores oportunidades para los trabajadores y en ofertar los productos del trabajo cada año de forma más accesible.

Esto genera una inevitable competencia entre empresarios por reducir precios sin perder sus ganancias, y esto es benévolo para la sociedad en su conjunto. De esta forma en las últimas seis décadas los precios han ido disminuyendo en los países capitalistas en relación a los salarios y al ahorro, elevando a muchos pobres a las clases medias y volviendo a la clase media más rica?

Una economía libre -capitalista- genera riqueza de acuerdo al aporte productivo de cada persona y empresa, premiando la innovación, el ahorro y la inversión. Porque para enriquecerse se debe atender las necesidades de los demás de forma consistente. Nada como una economía creciente como garantía de que cada generación tendrá acceso a mejores bienes materiales y culturales que la anterior.

Durante 8.000 años el ser humano no conoció otra cosa que la pobreza. Aunque más que hablar de pobreza habría que hablar de ausencia de riqueza, porque lo que se genera y se hereda no es la pobreza sino la riqueza ${ }^{8}$. Para Nathan Rosenberg, "la percepción de la pobreza como algo moralmente intolerable en una sociedad rica, tuvo que esperar a la aparición de una sociedad rica”. Incluso los "ricos" -la nobleza y los reyes- de hace 300 años envidiarían las condiciones de expectativa de vida,

\footnotetext{
${ }^{6}$ Cfr Fundación Heritage, Informe sobre la pobreza, 2006

${ }^{7}$ Aunque sin tener el total de estas condiciones, un caso latinoamericano insuficientemente reconocido es Chile, donde en los 15 años de mayor libertad económica la clase media paso de ser un $40 \%$ a ser un $65 \%$ de la población y recortándose igualmente el número de pobres de $40 \%$ al $17 \%$.

${ }^{8}$ Un pobre no es alguien que genera pobreza, sino alguien que no crea riqueza
} 
mortandad infantil, salud y acceso a otros bienes con las que una familia de clase media ecuatoriana cuenta actualmente. Al ritmo al que iban las cosas en la antigüedad, costaba casi 2.000 años duplicar el ingreso promedio en un país. Pero Inglaterra lo hizo en 60 años durante la Revolución Industrial, resultado de la libertad político-económica que las ideas de la Ilustración británica permitieron. Taiwán, Hong-Hong y China lo han logrado en menos de 10 años, por una sencilla razón: el know-how y los capitales ya están disponibles para el país relativamente pobre que se decida a liberalizar su economía y volverse un campo de juego estable para los empresarios de todo el mundo.

Shangai y Bombai son dos regiones del mundo donde sus ciudadanos han pasado en poco tiempo de la pobreza a la riqueza hasta el punto de que todos los destinos turísticos del mundo intentan captar ahora clientes de esas zonas. Son los nuevos ricos. No lo han logrado con limosna de otros países sino volviéndose capitalistas. Podemos llevarnos las manos a la cabeza por las condiciones laborales de sus ciudadanos pero no olvidemos que esos ciudadanos libres eligen esas condiciones antes que sus antiguos empleos en la agricultura. Las condiciones laborales en esas regiones irán mejorando conforme aumente su desarrollo empresarial. Recordemos que en Europa, y no hace muchos siglos, los niños también trabajaban. Ahora no. Y no ha sido gracias a la acción de ONGs pro derecho a la infancia sino gracias a la misma dinámica de enriquecimiento del capitalismo. Esas regiones están en una fase anterior a nosotros con la diferencia de que la globalización -el que puedan vender sus productos en el mundo entero- les permitirá salir antes de la pobreza.

¿Y por qué hay países como Zimbabwe que no levantan cabeza? Primero porque la historia de África desde que se tiene datos es la historia de un estado de guerra sin descanso. Esa situación no invita a hacer inversiones a medio ni largo plazo. ¿Cómo crear algo nuevo cuando tu principal problema es la supervivencia?

Otra razón es que en África la idea de contrato tiene poco valor. Muchos africanos con grandes virtudes humanas no entienden que lo pactado debe cumplirse aunque su cumplimiento sea costoso y en ocasiones perjudicial para una parte, quizás porque la cultura romana no hizo mella en esos pueblos. Los pocos empresarios que se atreven a poner una fábrica en el África subsahariana atraídos por el bajo coste laboral acaban cerrándola porque no pueden luchar ante una mentalidad de engaño continuo. Y el capitalismo crece y se apoya en la honradez. Si te doy un pagaré por una mercancía debes confiar que en que en la fecha de vencimiento en mi cuenta habrá dinero y yo debo creer que tu mercancía tiene las especificaciones que me dices. Si no hay confianza no hay grandes negocios. Los negocios en un ambiente de engaño se limitan a pequeños intercambios y al trueque.

Los grandes hombres de negocio tienen en común que han sido educados en el respeto reverencial hacia el contrato. Rockefeller con 16 años le pidió a su padre mil dólares para empezar su primer negocio. Su padre se los prestó pero con unas clausuras muy duras en caso de incumplimiento firmadas ante notario. A los dos años 
el futuro millonario había multiplicado por 200 aquellos mil dólares y le devolvió a su padre la cantidad prestada con sus intereses y los gastos del notario, ni un céntimo más ni un céntimo menos. Vivían en habitaciones contiguas.

Con trece años Bill Gates jugaba de vez en cuando al Béisbol, pero no lo suficiente como para comprarse unos guantes. Su hermana tenía unos y cuando Bill Gates se los pidió redactaron un contrato de uso y disfrute de los guantes que incluía reparaciones e indemnizaciones en caso de roturas. Aquel contrato estaba tan bien redactado por los dos hermanos que hubiese tenido plena validez ante un juzgado mercantil.

La mejor manera de ayudar al tercer mundo es la educación en los logros del derecho romano: el derecho contractual, el respeto a los contratos de propiedad... y la educación en los valores que han hecho de occidente un mundo más próspero: la honradez y el cumplimiento de los compromisos contractuales. Por eso no es educativo perdonar sistemáticamente la deuda que contraen con las empresas o Instituciones occidentales. Si mi empresa vende banderas a uno de estos países debo tener la seguridad de que me van a pagar. Si ellos piden esas banderas, deben asegurarse de que cumplirán con los plazos de pago. Todas las ventas que las empresas españolas hacemos a África están aseguradas por CESCE. Un ejecutivo de esta empresa aseguradora me dijo que era sorprendente la mala fe de los políticos y empresarios africanos a la hora de comprarnos a las empresas españolas maquinaria y armas sobre todo. Compran sin intención de pagar. Ese impago CESCE lo traspasa al Estado español pagando a las empresas el 80\% normalmente. Y así crece la deuda. A menudo el Estado español, a través de acuerdos de inmigración por ejemplo, condona el 100\% de la deuda que pasamos a pagarlos los españoles con los impuestos. Pero al año, esos países vuelven a comprar y vuelven a endeudarse, sólo que con más rapidez que antes porque la jugada les ha salido bien. Hay otras poderosas razones para no perdonar la deuda externa'. Así como la causa del reciente enriquecimiento de Shangai y Bombai

${ }^{9}$ Otras razones para no condonar la deuda externa:

- Si se perdonan las deudas a los países en desarrollo, los bancos y, en general, las instituciones financieras, privadas y públicas, e incluso los gobiernos, no estarán dispuestos a conceder nuevos préstamos a estos países; con lo cual se habrá aliviado la situación actual, a cambio de cerrar las posibilidades del futuro.

- Perdonar total o parcialmente la deuda a todos los países clasificados como muy pobres, en forma indiscriminada, crea un problema de justicia comparativa entre los países que realizan esfuerzos para el ajuste estructural y los que no hacen nada en esta línea.

- Existe un problema de discriminación entre acreedores, en favor de los privados, que no están sujetos a las decisiones del Club de París, o del Banco y el Fondo. Este argumento, sin embargo, no parece tener mucha fuerza, ya que los bancos privados que, por lo general, no prestaron a los países que hoy son candidatos al perdón, ya resolvieron sus problemas, acogiéndose a la propuesta Brady, aunque fuera a costa de cancelar parte de sus créditos, cedidos con más o menos descuento

- La cancelación de las deudas dañaría la solvencia del FMI, el cual endurecería su financiación aumentando nuestros impuestos, rebajando la competitividad de nuestras empresas y aumentando el desempleo

- La condonación e incluso la reducción de la deuda, sin condiciones, va en contra de los principios básicos del derecho mercantil, generando en los prestatarios la idea de que se puede pedir dinero sin preocuparse de su devolución. 
está en ellos mismos, el menor enriquecimiento de otros países como Zimbabwe también está en ellos.

Aún así, el enriquecimiento es global a distintas velocidades. Como dice el sueco Johan Norberg: "Desde luego, el europeo occidental o norteamericano es 19 veces más rico que en 1820, pero un latinoamericano es 9 veces más rico, un asiático 6 veces más rico y un africano cerca de 3 veces más rico". Así es que, ¿de quién fue robada esa riqueza? El capitalismo no es un juego de suma cero ${ }^{10}$ en el que la riqueza de unos es producida a costa de la pobreza de otros. La riqueza no es como la energía o la materia que ni se crea ni se destruye, sólo se transforma. No. La riqueza sí se genera de la nada y sí desaparece. temporales?

¿Y qué pasa con los más necesitados y los que caen en desgracias

Existe la creencia falsa de que el actual modelo de estado protector y socialista extremo, sube la renta de los más desfavorecidos porque aumenta la redistribución de riquezas de ricos a pobres. Según este supuesto, un Estado liberal y capitalista que fomente el enriquecimiento de las empresas, fomenta una actitud egoísta y despreocupada respecto a los más necesitados.

En realidad nuestro Estado benefactor y socialista desincentiva la iniciativa, el trabajo productivo y la generosidad. En cambio, las sociedades que valoran el logro, que admiran en vez de envidiar, que producen riqueza en vez de pedir, tienden también a ser generosas en casos que auténticamente requieren de la ayuda de la comunidad ${ }^{11}$.

Y además el capitalismo permite ir ascendiendo en nuestra escala de necesidades, superando las más primarias y permitiéndonos pensar en los demás y contar con los recursos para apoyarles. El día en que el ser humano experimente vivir en sociedades libres, ayudar ya no será una imposición estatal que le quita todo valor ético y cultural, ni el resultado de una falsa mala conciencia. La generosidad simplemente se volverá la regla y no la excepción dado que la sociedad civil habrá sentido su rol -no el de políticos y burócratas- la ayuda a los más necesitados.

Existe un dilema intelectual, ético, político y vital real y debemos optar: más capitalismo o más socialismo. Por un lado: más libertad, más enriquecimiento, menos pobreza, o por otro lado: más intervencionismo estatal, más redistribución, más clase pasiva. No seamos ingenuos. No vale colocarnos en un supuesto justo medio entre ambas posturas como si esa posición fuese superior y elevadora de las posturas enfrentadas. En realidad, vivimos en ese punto medio. Nuestros políticos no pueden prescindir de las empresas e introduce un nivel altísimo de pago de impuestos. Así

\footnotetext{
${ }^{10}$ Como tantas veces ha explicado Leonardo Polo

${ }^{11}$ Como dijo el filósofo objetivista y psicólogo Nathaniel Branden: "Existe evidencia abrumadora de que mientras más alto el nivel de autoestima, más propenso será uno a tratar a los demás con respeto, gentileza y generosidad".
} 
lastran gravemente el crecimiento de las empresas y por tanto la creación de riquezas y de empleos. El punto medio es esto que vivimos: el socialismo, consolidado en España durante décadas de franquismo y continuado en mayor o menor medido por los partidos de la democracia.

¿Y a qué nos ha llevado el socialismo? A que cuando se produce una crisis nadie tiene dinero. ¿Quién se ha enriquecido con el boom de la construcción? Los trabajadores y los empresarios de la construcción, pero sobre todo los ayuntamientos que han vendido el suelo. Con ese dinero han multiplicado los gastos sociales, muy buenos todos, pero desproporcionados. Cuando se vendía suelo, los ayuntamientos y las CCAA se han dedicado a gastar más. El político gasta lo que le llega a sus manos y siempre gasta más (por eso se endeuda). El político no ahorra, quienes ahorran dinero somos los ciudadanos libres a quienes nos cuesta ganarlo y sí nos preocupamos por nuestro futuro. La cuestión no es si el político es bueno o malo. Quitando a Pol Pot, Mao o Hitler, suelen ser buena gente: pero buena gente que disponen de una media de $100.000 €$ al mes para gastar en cosas buenas. Como siempre le quedan cosas buenas por hacer, y como las que hacen siempre se pueden hacer mejor, gastan más y más. Sobre todos los socialistas. No me preocupa lo de los sueldos, los coches oficiales y las obras en sus despachos. No deja de ser algo anecdótico en el conjunto del PIB nacional. Lo preocupante es el gasto en cosas buenas, sobre todo sanidad y educación. ¿Debemos gastar en sanidad y educación? Sí, pero nosotros directamente, no a través del Estado.

Al llegar la crisis, el Estado se está endeudando peligrosamente para inyectar dinero a los ayuntamientos y a las Comunidades que están al borde de la ruina porque se les ha cortado su vía de financiación: venta de suelo, IVA e Impuestos de Sociedades. Esa inmensa fortuna de nuestros impuestos que está llegando a los ayuntamientos y a las Comunidades es para pagar los gastos que ya tenían comprometidos el año pasado. ¿Y qué va a pasar el año que viene? ¿Seguirá el Estado español aumentando la deuda? Está hipotecando el futuro de las generaciones que vienen, que son los que pagarán tanta deuda.

La macro estructura de Organismos públicos que se solapan, más las empresas públicas, universidades públicas, colegios públicos, hospitales públicos, tres millones de funcionarios, cuesta mucho. En épocas de bonanza no había problemas. Ahora que las empresas españolas producen menos, se descubre que vivimos por encima de nuestras posibilidades. Los precios de los bienes que vuestros padres han pagado durante su vida de trabajo están tan hinchados por los impuestos, que con ese dinero más los impuestos directos que les han deducido durante décadas podrían haberos pagado no una sino dos carreras universitarias, y un seguro privado en un hospital, y un coche deportivo. Con la diferencia además de que las Universidades competirían entre sí para captar y fidelizar alumnos. Porque ¿cuántos premios nóveles ha dado las decenas de Universidades públicas levantadas a golpes de impuestos?. Cuando yo estudiaba filosofía, nos presentábamos a los exámenes unos once alumnos de veinte matriculados (es los que tiene que el Estado te pague la 
carrera $^{12}$ : algunos no lo valoran). Había dos profesores que sólo nos hacían un examen al año en junio y no colgaban las notas en las puertas de sus despachos hasta la primera semana de agosto. Siete semanas para corregir once exámenes, con la tensión que eso provoca. Esos dos profesores siguen en la actualidad dando clases con un sueldo que ronda los $3.000 €$ (es lo que tiene ser funcionario público).

El título de este simposio es "La crisis como condición previa y necesaria para el nacimiento de nuevas teorías”, y añado: ... y para el nacimiento de nuevas actitudes éticas. El único efecto positivo de esta dramática crisis será darnos cuenta de que el socialismo fagocitario del dinero ajeno nos ha dejado sin recursos para reaccionar, y eso daña sobre todo a los más pobres. Ahora es un buen momento para optar de una vez por el capitalismo que nos hace más ricos y más libres.

Si parte del dinero que las empresas españolas han dado en impuestos se hubiera quedado en sus cuentas, habrían ahorrado e invertido y ahora habría muchas más oportunidades de empleo, y los empleos estarían mejor remunerados. Y ya les digo, no hay existe nueva opción hacia el punto medio porque el punto medio es el socialismo en el que estamos inmersos.

$* * * * *$

Juan Antonio Moreno Urbaneja es doctor en filosofía por la Universidad de Málaga y gerente de Adivin, que incluye una Fábrica de Mástiles \& Banderas, una plataforma de venta online y una editorial cuya revista más destacada es la guía GO!

Publicaciones recientes:

Ha escrito siete libros sobre economía y filosofía (cinco ya están publicados): entre otros: "El método en la filosofía agustiniana" y "Claves actuales de la epistemología de la ciencia". Ahora va a publicar otro libro sobre la crisis económica, del cual este trabajo es un resumen.

Dirección electrónica:

jam@adivin.com

proceso de selección del trabajo:

solicitado: 1 de enero de 2009

recibido: 13 de abril de 2009

aceptado: 13 de abril de 2009

\footnotetext{
${ }^{12}$ Con los $2.800 €$ que pagáis al año no cubrís ni una nómina y media de un bedel.
} 